\title{
Integration of Lean Approach with Energy Efficiency: Application in Kitchenware Manufacturing Company
}

\author{
Muhittin Sagnak \\ Department of Information and Document Management, \\ Izmir Kâtip Celebi University, \\ Balatcik Kampusu, 35620, Cigli, Izmir, Turkey. \\ E-mail: muhittin.sagnak@ikcu.edu.tr \\ Erhan Ada \\ Department of Business Administration, \\ Yasar University, Universite Caddesi, \\ No: 37-39, Bornova, Izmir, Turkey. \\ E-mail: erhan.ada@yasar.edu.tr \\ Yigit Kazancoglu \\ Department of Logistics Management, \\ Yasar University, Universite Caddesi, \\ No: 37-39, Bornova, Izmir, Turkey. \\ Corresponding author: yigit.kazancoglu@yasar.edu.tr \\ Atul Mishra \\ Plymouth Business School, \\ University of Plymouth, Plymouth, UK. \\ E-mail: atul.mishra@plymouth.ac.uk
}

(Received June 1, 2020; Accepted August 1, 2020)

\begin{abstract}
Energy efficiency in the industries is one of the leading problems of the 21 st century. The main aim for the companies to deal with the energy efficiency paradigm is to save the resources in the manufacturing operations. Manufacturing operations involve activities that creates wastes in any case; therefore, these wastes should be eliminated, or minimized as much as possible. In this paper, it is aimed to integrate the energy efficiency term with lean management principles. The barriers and the drivers of the energy efficiency was discussed, and the 8 wastes within lean perspective were translated into energy counterparts. 8 wastes of lean approach were defined as energy efficiency perspective, and used as criteria. The study will reveal the important criteria using Fuzzy Analytic Network Process (Fuzzy ANP) method to make implications about how to eliminate these wastes.
\end{abstract}

Keywords- Energy efficiency, Lean production, Fuzzy analytic Network process.

\section{Introduction}

Energy efficiency in the industries is one of the leading problems of the 21 st century. Great efforts have been spent to assess energy efficiency after the publication of the 2005/32/EC eco-design instructions in 2005. In addition, a Horizon 2020 program promoted energy efficiency topic to save the resources and control global warming drivers such as $\mathrm{CO}_{2}$ emissions (Schudeleit et al., 2016). The ISO 50001 (ISO, 2011) identified energy efficiency as "ratio or other quantitative relationship between an output of performance, service, goods or energy, and an input of energy". For this reason, efficiency is not only a measure of achieving the goal, but also a measure of the relationship 
International Journal of Mathematical, Engineering and Management Sciences

Vol. 5, No. 6, 1128-1139, 2020

https://doi.org/10.33889/IJMEMS.2020.5.6.086

between the instruments and the effect. Increasing energy efficiency aims to achieve the greatest possible result with low energy consumption (Schudeleit et al., 2016).

The International Energy Agency considers energy efficiency as a goal of reducing energy demand for products or services, or achieving the same result with less energy input (Salonitis and Ball, 2013). The Chinese national standard regards energy efficiency as the rate or other numerical relationship between the input and output of the energy instruments. The term "energy efficiency" is very common, world-wide used term, and thus, has a different meanings in terms of applications in different environments (Zhou et al., 2016). A technically-based person will describe energy efficiency from a thermodynamics perspective (Patterson, 1996), which is the rate of input energy and output to evaluate the level of energy conversion. From a manufacturing perspective, energy efficiency in terms of physical thermodynamics is used and known as input-output efficiency, which is found as the rate of the product output to the total energy input (Neto et al., 2009).

Energy efficiency term refers to the ability to use less energy input in the economy (Iftikhar et al., 2018). To overcome the critical situations such as increased energy prices, exhaustion of global resources, and global climate warming, improving energy efficiency is a certain trend to save energy, reduce emissions, and provide sustainability. Basically, modeling of energy consumption of machine tools and evaluation of energy efficiency are the prerequisite for energy-saving in production (Zhou et al., 2016).

Energy efficiency and investments for clean environments can be seen as two key mechanisms to accomplish the objectives of EU energy and climate package trio by 2020:1) to decrease the greenhouse gas emissions by 20\% until 2020 (with regard to 1990 levels); 2) to increase renewable energy sources by $20 \%$ of gross energy consumption; and 3) to reduce energy consumption by $20 \%$ (Hrovatin et al., 2016).

In this paper, it is aimed to integrate the energy efficiency term with lean management principles. The barriers and the drivers of the energy efficiency was discussed, and the 8 wastes within lean perspective were translated into energy counterparts. The main contribution of this study is to integrate the energy efficiency concept with lean approach. 8 wastes of lean approach were defined as energy efficiency perspective, and used as criteria. The study will reveal the important criteria using Fuzzy Analytic Network Process (Fuzzy ANP) method to make implications about how to eliminate these wastes.

Following the introduction, section 2 clarified the barriers and drivers in energy efficiency literature. Lean integration was clarified in section 3. Fuzzy ANP method was presented in section 4. Section 5 describes the application of this study. Section 6 summarizes the implications, and finally, section 7 , includes the conclusion, and discusses future research directions.

\section{Barriers and Drivers}

Although the benefits of energy efficiency measures are clear, companies have difficulties to implement energy efficiency policies because of the current barriers that need to be defined in order to state motivational strategies that can overcome those barriers (Henriques and Catarino, 2016).

A critical hurdle for investing in energy efficiency concerns the restriction on access to non-profitable investments, as it usually means a high price for capital. As a result, only the investments which have returns larger than this (high) hurdle rate will be realized (Schleich and Grubber, 2008). 
International Journal of Mathematical, Engineering and Management Sciences

Vol. 5, No. 6, 1128-1139, 2020

https://doi.org/10.33889/IJMEMS.2020.5.6.086

In addition, limited resources and lack of time for energy efficient options, lack of information that does not make clear the amount of energy used, and lack of ability to demonstrate energy efficiency projects are the other barriers for the companies (Henriques and Catarino, 2016). Lack of experience with energy efficiency leads to an increase in concerns that energy efficiency measures may lead to interruption of the production process, lead to revenue losses, or affect product quality (Olsthoorn et al., 2015).

Although the main attempt was engaged with the investigation of barriers, there are also some efforts to describe the drivers of energy efficiency investments. Reddy (2013) specified drivers as any factor that helps the investment become more profitable. Thollander and Ottosson (2008) claimed that they involve different factors, both emphasizing investments in energy-efficient and cost-effective technologies. Cagno and Trianni (2013) pointed to the need for drivers to be understood as both energy-efficient technologies and factors that facilitate the adoption of applications. Drivers can be understood as all factors that support energy efficiency investments in both domestic and external sectors. Similar to the barriers, the authors developed various types of drivers. Reddy (2013) exemplified six drivers: awareness, reduction in technology prices, rise in energy prices, attraction of technology, non-energy benefits, and environmental regulations. According to Cagno and Trianni (2013), this classification is lacking and completely theoretical without empirical validation. They spent the first effort to classify the drivers according to the empirical evidence Thollander and Ottosson (2008). Cagno and Trianni (2013) categorized the drivers into three groups: 1) market-driven propulsive forces (cost reductions due to energy use, rising energy prices and threat of international competition); 2) current and potential energy policies (subsidies or beneficiary loans for energy efficiency investments, information provision by energy experts and publiclyfinanced energy audits); and 3) organizational and behavioral factors (company's "green" image, self-dedicated managers, long-term energy strategies, environmental management systems and better working conditions). Chai and Yeo (2012) specified the categorization of drivers more simple by indicating only two classes for motivators: economic (reduction of operating expenses) and environmental (being a good corporate citizen).

Within this perspective, the literature needs a new approach to energy efficiency paradigm emphasizing the elimination, or minimization of wastes. Some barriers can be eliminated, and some drivers may gain strength through the instrumentality of lean approach integration into energy efficiency.

\section{Lean Integration}

Increasing the rate of energy efficiency in processes can decrease energy consumption, reduce environmental impact and help sustainable production (Pusavec et al., 2010). There are many reasons to reduce the environmental impact of producers, but many are missing the opportunities to be more environmentally-friendly without having to make significant investments. The lean approach can be a solution for those missing opportunities by designing a new green manufacturing system that decreases the $\mathrm{CO}_{2}$ emission by 10 to $15 \%$ (Gonce and Somers, 2010).

Most of the companies are not successful for improving energy efficiency for 3 reasons: 1) in times gone, energy prices were too low to bring high efficiency to the management agenda, 2) most of the companies' focus was on volume growth and quality optimization, and 3) the management of energy consumption was a difficult task as it is very reactive to externalities such as production rate and product mix. Improved energy efficiency cannot be applied from the outside as a new technology or energy source. Instead, it must be rigorous in every aspect of the production process. To 
International Journal of Mathematical, Engineering and Management Sciences

Vol. 5, No. 6, 1128-1139, 2020

https://doi.org/10.33889/IJMEMS.2020.5.6.086

adapt this takes time, and requires commitment and a new way of thinking. Fortunately, many firms already include the bases needed to improve energy efficiency. Lean organizations that use integrated processes have the basic skills needed to maximize energy efficiency. Actually, many lean applications increase energy efficiency as a side effect. The wastes such as overproduction, transportation, and quality defects may be linked with energy consumption; therefore, if these wastes are eliminated, energy efficiency will increase (Gonce and Somers, 2010). For this reason, lean thinking can be used as an approach to enhance the performance of operational and environmental activities through dissemination, reduction of pollution cost, and efficient use of energy and resources (Souza and Alves, 2018).

Lean manufacturing, also called Toyota Production System, was originated at Toyota Motor Company (Womack et al., 1991). With reference to Ohno (1988), who was labeled as the father of TPS, the seven wastes of lean manufacturing are identified as overproduction, waiting, transportation, over-specification, inventory, rework/scrap, and motion. Womack and Jones (2003) introduced employee potential as the 8th waste (Sagnak and Kazancoglu, 2016).

The energy-related wastes, and the wastes caused by environmental activities are not directly included in 8 wastes of TPS. However, it does not mean that, these wastes are not related to the lean approach. The energy-related, and environmental wastes can be associated with the 8 wastes (Environmental Protection Agency (EPA), 2011). By modifying some of the lean tools to analyze energy efficiency, the companies are also trying to find out some opportunities for $\mathrm{CO}_{2}$ reduction. Within lean perspective, the eight sources of waste can be translated into the energy terms. Table 1 shows the lean waste concept translated into energy terms.

Table 1. Eight kinds of waste for energy (environmental protection agency (EPA), 2011)

\begin{tabular}{ll}
\hline Type of Waste & Definition \\
\hline Overproduction (C1) & Consumption of unnecessary energy for unnecessary products \\
Waiting (C2) & Consumption of unnecessary energy when production is stopped \\
Transportation (C3) & Consumption of unnecessary energy for transportation \\
Over-specification (C4) & Consumption of unnecessary energy for unnecessary processing \\
Inventory (C5) & Consumption of unnecessary energy for inventory storage and \\
& warehousing space \\
Rework/scrap (C6) & Consumption of energy for defective products \\
Motion (Inefficient processes) (C7) & Consumption of energy for inefficient processes \\
Employee Potential (C8) & Failure to use employees potential to identify and prevent energy \\
& waste \\
\hline
\end{tabular}

Thus, 8 wastes of lean approach in terms of energy efficiency perspective were defined. Next section was prepared to represent the methodology.

\section{Methodology}

\subsection{Fuzzy Sets Theory}

Due to the subjective manners, the decision-makers deal with uncertainties in the decision-making process. Introduced by Zadeh (1965), fuzzy set theory enables the usage of linguistic terms to overcome this kind of subjectivity and vagueness of human judgment. A class of objects with a continuum of membership grades is called a fuzzy set. A tilde " $\sim$ " is placed above when a fuzzy set is represented (Zadeh, 1965). 
International Journal of Mathematical, Engineering and Management Sciences

Vol. 5, No. 6, 1128-1139, 2020

https://doi.org/10.33889/IJMEMS.2020.5.6.086

There are various fuzzy membership functions. In this paper, triangular fuzzy numbers were used. A triangular fuzzy number is indicated as $\left(\mathrm{l}_{\mathrm{ij}}, \mathrm{m}_{\mathrm{ij}}, \mathrm{r}_{\mathrm{ij}}\right)$ referring the smallest possible, the most likely, and the largest possible values, respectively.

\subsection{Fuzzy Analytic Network Process \\ 4.2.1 Analytic Network Process}

The Analytic Network Process (ANP) is the most commonly-used approach for decision-making analysis. Proposed by Saaty (1996), it is formed as a network, rather than the hierarchy used in Analytic Hierarchy Process (AHP). Under AHP, the decision-making process is broken down into a top-down linear relationship with independent criteria at each level (Meade and Sarkis, 1999). However, in ANP, there is a relationship between the clusters (outer dependence) themselves, and the criteria within the clusters (inner dependence). In other words, the criterion for a cluster may affect any criterion in same cluster, or any other cluster (Önüt et al., 2009). The main aim is to identify the overall importance weights of all criteria.

Hierarchy may be an inappropriate structure for defining a decision problem in which higher-level clusters are dependent on lower-level clusters (Saaty, 1996). A network system is preferred to a hierarchy when there is a feedback between clusters. Saaty (1996) suggested using AHP where the alternatives or criteria are independent, and ANP where dependent.

The process of modelling contains three major steps (Önüt et al., 2009):

Step 1: Pairwise comparisons and priority vectors: Like AHP, in ANP, pairwise comparisons are used to identify the connections and priorities between the criteria and clusters. The clusters and the criteria of each cluster are compared pairwise, based on internal and external dependencies (Chung et al., 2005). Decision-makers weigh the two clusters or two criteria based on their relative importance regarding upper-level cluster or criterion. They indicated their assessments using Saaty's scale (Saaty, 1980). Saaty's scale allows decision-makers determine the relative weights by representing their judgments in linguistic terms as equally important (E), moderately more important (MM), strongly more important (SM), very strongly more important (VSM), and extremely more important (EM). The linguistic terms are then converted into numerical values, 1, 3, 5, 7, 9, respectively. The intermediate values, $2,4,6$, and 8 are used to reflect compromise between the above values. The relative importance of the criterion $i$ to criterion $j$ is indicated by a score of $a_{i j}$, i.e., $a_{i j}=w_{i} / w_{j}$. A reciprocal value is found by comparing inversely, that is, $a_{i j}=1 / a_{j i}$, indicating that criterion $j$ is more important than criterion $i$ (Önüt et al., 2009).

The pairwise comparison matrix, $A$, is defined as follows:

$$
A=\left[\begin{array}{lll}
w_{1} / w_{1} & w_{1} / w_{2} \cdots & w_{1} / w_{n} \\
w_{2} / w_{1} & w_{2} / w_{2} \cdots & w_{2} / w_{n} \\
\vdots & \vdots & \vdots \\
w_{n} / w_{1} & w_{n} / w_{2} \cdots w_{n} / w_{n}
\end{array}\right]=\left[\begin{array}{lccc}
1 & a_{12} & \cdots & a_{1 n} \\
1 / a_{12} & 1 & \cdots & a_{2 n} \\
\vdots & \vdots & & \vdots \\
1 / a_{1 n} & 1 / a_{2 n} & \cdots & 1
\end{array}\right] .
$$

Likewise, in AHP, an eigenvector (local priority vector), w, is calculated by following equation: 
International Journal of Mathematical, Engineering and Management Sciences

Vol. 5, No. 6, 1128-1139, 2020

https://doi.org/10.33889/IJMEMS.2020.5.6.086

$$
A \times w=\lambda_{\max } \times w
$$

where, $\lambda_{\max }$ is the biggest eigenvalue of matrix $\mathrm{A}$.

Step 2: Initial supermatrix formation: As stated by Saaty (1996), a supermatrix is a concept similar to Markov chains process. Saaty (2001) argued that a supermatrix approach was appropriate for reflecting the relationships of the network, and finding the criteria weights. A supermatrix is a segmented matrix in which each matrix part incorporates a relationship (Meade and Sarkis, 1999).Let the clusters of a decision system be $C_{k}, k=1, \ldots, n$, and each cluster $k$ has $m_{k}$ criteria, indicated by $e_{k 1}, e_{k 2}, \ldots, e_{k m_{k}}$. A standard supermatrix is shown as follows (Lee et al., 2008):

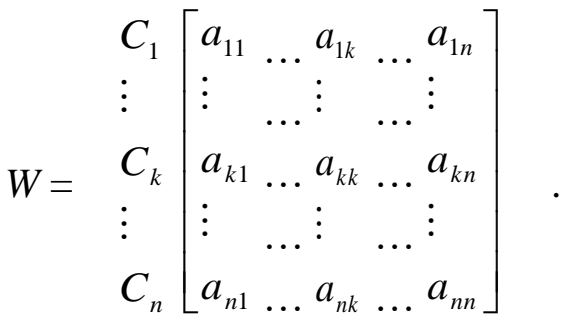

For example, $a_{k l}$ block shows the relative importance of cluster $k$ regarding cluster 1 , in other words, it symbolizes the effect of cluster $k$ on each of the cluster 1 (Chung et al., 2005).

Step 3: Weighted Supermatrix formation: An eigenvector is acquired by pairwise comparison of the row criterion with the column criterion. The weighted supermatrix is obtained by weighing the supermatrix by multiplying the first entry of the respective eigenvector with all elements in the first block of that column, second entry with second block, and so on (Chung et al., 2005).

The limit supermatrix, which has the same form with weighted supermatrix, is obtained by taking power of weighted supermatrix to limiting powers in order to sustain the cumulative influence of each criterion on every other criterion interacted (Saaty and Vargas, 1998). The final priorities of all criteria can be found by normalizing each block of the limit supermatrix, in which all the columns are same (Chung et al., 2005).

\subsubsection{Fuzzy ANP: Fuzzy Extension of ANP}

In this study, fuzzy logic is integrated to ANP methodology. Triangular fuzzy numbers are used in order to constitute the pairwise comparison matrices. Fuzzy ANP conforms to the relationships between clusters and criteria using supermatrices to calculate the relative importance weights (Önüt et al., 2009).

Although Saaty's (1980) scale of 1-9 has the advantages of simplicity and convenience, decisionmakers experience uncertainties because of the subjective manner of their judgments, therefore pairwise comparison matrices are constructed by using triangular fuzzy numbers $(1, \mathrm{~m}, \mathrm{r})$ in which $l \leq m \leq r$. The parameters $l, m$, and $r$ indicate the smallest possible value, the most likely value, and the most promising value, respectively. The fuzzy matrix is shown as follows (Önüt et al., 2009). 
International Journal of Mathematical, Engineering and Management Sciences

Vol. 5, No. 6, 1128-1139, 2020

https://doi.org/10.33889/IJMEMS.2020.5.6.086

$$
\tilde{A}=\left(\begin{array}{cccc}
\left(a_{11}^{l}, a_{11}^{m}, a_{11}^{u}\right) & \left(a_{12}^{l}, a_{12}^{m}, a_{12}^{u}\right) \ldots & \left(a_{1 n}^{l}, a_{1 n}^{m}, a_{1 n}^{u}\right) \\
\left(a_{21}^{l}, a_{21}^{m}, a_{21}^{u}\right) & \left(a_{22}^{l}, a_{22}^{m}, a_{22}^{u}\right) \ldots & \left(a_{2 n}^{l}, a_{2 n}^{m}, a_{2 n}^{u}\right) \\
\vdots & \vdots & \vdots & \vdots \\
\left(a_{m 1}^{l}, a_{m 1}^{m}, a_{m 1}^{u}\right) & \left(a_{m 1}^{l}, a_{m 1}^{m}, a_{m 1}^{u}\right) & \ldots & \left(a_{m n}^{l}, a_{m n}^{m}, a_{m n}^{u}\right)
\end{array}\right) .
$$

The $a_{m n}$ reflects the pairwise comparison of criterion m (row) with criterion $\mathrm{n}$ (column). The pairwise comparison matrix $(\tilde{\mathrm{A}})$ is supposed as reciprocal.

$$
\tilde{A}=\left(\begin{array}{cccc}
(1,1,1) & \left(a_{12}^{l}, a_{12}^{m}, a_{12}^{u}\right) & \ldots & \left(a_{1 n}^{l}, a_{1 n}^{m}, a_{1 n}^{u}\right) \\
\left(\frac{1}{a_{12}^{u}}, \frac{1}{a_{12}^{m}}, \frac{1}{a_{12}^{l}}\right) & (1,1,1) & \ldots & \left(a_{2 n}^{l}, a_{2 n}^{m}, a_{2 n}^{u}\right) \\
\vdots & \vdots & \vdots & \vdots \\
\left(\frac{1}{a_{1 n}^{u}}, \frac{1}{a_{1 n}^{m}}, \frac{1}{a_{1 n}^{l}}\right)\left(\frac{1}{a_{2 n}^{u}}, \frac{1}{a_{2 n}^{m}}, \frac{1}{a_{2 n}^{l}}\right) & \ldots & (1,1,1)
\end{array}\right) .
$$

Logarithmic least squares method which can be seen as follows can be used to estimate the fuzzy priorities (Chen and Hwang, 1992).

$$
\tilde{W}=\left(W_{k}^{l}, W_{k}^{m}, W_{k}^{u}\right) \quad k=1,2,3, \ldots, n
$$

where,

$$
W_{k}^{s}=\frac{\left(\prod_{j=1}^{n} a_{k j}^{s}\right)^{1 / n}}{\sum_{i=1}^{n}\left(\prod_{j=1}^{n} a_{i j}^{m}\right)^{1 / n}}, \quad s \in\{l, m, u\} .
$$

\section{Application}

The application was conducted in kitchenware manufacturing company located in Izmir, Turkey. The company has three manufacturing lines; hob, oven, and hood fume. The manufacturing lines are organized as assembly lines which have bidirectional flows. All activities are recorded just as actualized, and the performance losses are reported at the same time. The manufacturing system works online.

In data collection process, the pairwise comparisons were conducted with 18 experts. These experts from the company were the general manager, deputy general manager, the plant manager, the operations manager, the supply chain manager, and the operations department personnel. The pairwise comparisons were made by the authorities responsible for lean management activities with the consent of the Board of Directors.

The pairwise comparison matrices should be constructed with the help of linguistic terms shown in Table 2. 
International Journal of Mathematical, Engineering and Management Sciences

Vol. 5, No. 6, 1128-1139, 2020

https://doi.org/10.33889/IJMEMS.2020.5.6.086

Table 2. Comparison scale

\begin{tabular}{lcc}
\hline Linguistic Variables & Scale of Fuzzy Number & Scale of Reciprocal Fuzzy Number \\
\hline Equal $€$ & $(1,1,1)$ & $(1 / 1,1 / 1,1 / 1)$ \\
Moderate $(\mathrm{M})$ & $(2,3,4)$ & $(1 / 4,1 / 3,1 / 2)$ \\
Strong (S) & $(4,5,6)$ & $(1 / 6,1 / 5,1 / 4)$ \\
Very Strong (VS) & $(6,7,8)$ & $(1 / 8,1 / 7,1 / 6)$ \\
Absolute $(\mathrm{A})$ & $(8,9,10)$ & $(1 / 10,1 / 9,1 / 8)$ \\
\hline
\end{tabular}

Table 3 shows one of the experts' judgments.

Table 3. The judgments of expert 1

\begin{tabular}{ccccccccc}
\hline & $\mathrm{C} 1$ & $\mathrm{C} 2$ & $\mathrm{C} 3$ & $\mathrm{C} 4$ & $\mathrm{C} 5$ & $\mathrm{C} 6$ & $\mathrm{C} 7$ & $\mathrm{C} 8$ \\
\hline $\mathrm{C} 1$ & 1 & $\mathrm{M}$ & $\mathrm{E}$ & $\mathrm{S}$ & $\mathrm{M}$ & $\mathrm{S}$ & $\mathrm{S}$ & $\mathrm{M}$ \\
$\mathrm{C} 2$ & 1 & $1 / \mathrm{M}$ & $\mathrm{M}$ & $\mathrm{E}$ & $\mathrm{M}$ & $\mathrm{M}$ & $\mathrm{E}$ \\
$\mathrm{C} 3$ & & 1 & $\mathrm{~S}$ & $\mathrm{M}$ & $\mathrm{S}$ & $\mathrm{S}$ & $\mathrm{M}$ \\
$\mathrm{C} 4$ & & & 1 & $1 / \mathrm{M}$ & $\mathrm{E}$ & $\mathrm{E}$ & $\mathrm{E}$ \\
$\mathrm{C} 5$ & & & & 1 & $\mathrm{M}$ & $\mathrm{M}$ & $\mathrm{E}$ \\
$\mathrm{C} 6$ & & & & & 1 & $\mathrm{E}$ & $\mathrm{E}$ \\
$\mathrm{C} 7$ & & & & & & 1 & $\mathrm{E}$ \\
$\mathrm{C} 8$ & & & & & & & & 1 \\
\hline
\end{tabular}

Then, those expressions were converted into fuzzy numerical values by a comparison table, seen in Table 2. In order to take into consideration of all experts' opinions, the geometric mean of all matrices were calculated.

The normalized fuzzy criteria weights, which can be seen in Table 4, were obtained by employing Step 3.

Table 4. Normalized fuzzy criteria weights

\begin{tabular}{lccc}
\hline Criteria & 1 & $\mathrm{~m}$ & $\mathrm{r}$ \\
\hline Overproduction & 0.165791 & 0.204332 & 0.239971 \\
Transportation & 0.123487 & 0.14353 & 0.162943 \\
Waiting & 0.168689 & 0.207357 & 0.241703 \\
Over-specification & 0.07321 & 0.080778 & 0.091978 \\
Inventory & 0.10384 & 0.118426 & 0.134664 \\
Rework/scrap & 0.064847 & 0.072373 & 0.084344 \\
Motion & 0.068801 & 0.07549 & 0.085819 \\
Employee Potential & 0.093586 & 0.097713 & 0.10384 \\
\hline
\end{tabular}

Since all the numerical values were fuzzy, they were defuzzified using Opricovic and Tzeng's (2003) defuzzification method. Table 5 shows the defuzzified and normalized criteria weights in descending order.

Table 5. Defuzzified criteria weights

\begin{tabular}{lc}
\hline Criteria & Weights \\
\hline Overproduction & 0.229976 \\
Waiting & 0.211546 \\
Transportation & 0.130673 \\
Inventory & 0.088766 \\
Rework/scrap & 0.07052 \\
Employee Potential & 0.069553 \\
Over-specification & 0.060572 \\
Motion & 0.058114 \\
\hline
\end{tabular}


International Journal of Mathematical, Engineering and Management Sciences

Vol. 5, No. 6, 1128-1139, 2020

https://doi.org/10.33889/IJMEMS.2020.5.6.086

Within the lean perspective, firstly, the most important waste to provide energy efficient manufacturing process is found as overproduction with a weight of 0.229 . Secondly, waiting is another waste that has to be eliminated. The weight of it is 0.211 . Thirdly, transportation is another waste with a weight of 0.130 .

\section{Implications}

Overproduction is one of the main wastes of lean approach. If the companies face with overproduction problem in their manufacturing processes, it means, the companies are keeping excess inventory. It does not only constitute an unnecessary cost for excess inventory operations, but also covers other problems existing in the enterprise. These inventories lead to overpopulation of labor, different security stock problems and excess product that will occur during the production process. All of these are costs for the enterprise separately. Due to this reason, excess inventory should not be kept in the enterprises. Within the energy perspective, a waste of overproduction means spending excess energy in excess production. It is not only a waste about spending excess energy, but also a waste for other problems generated by overproduction.

Transportation carried out in the manufacturing line does not add any value to the product. Every transfer between workstations is a waste of time, energy, and resources. These operations, which do not add value but are necessary, should be minimized by avoiding excessive efforts. Within the energy perspective, a waste of transportation means spending excess energy in excess production. It is not only a waste about spending excess energy, but also a waste for other problems generated by transportation. Also, according to the Environmental Protection Agency (EPA) (2011), personnel travel, product shipments, and transportation in the form of product movement between plants are often a major contributor to the company's greenhouse gas emissions. Companies can significantly decrease greenhouse gas emissions using a variety of tools such as recruitment programs for employees, alternative fuels, and well-planned on-time deliveries.

Table 6 shows the details for the losses in the manufacturing line. Within lean perspective, all these losses can be associated with waiting waste.

Table 6. The losses in the manufacturing line

\begin{tabular}{lc}
\hline Manufacturing Line Losses & Rate \\
\hline Reprocessing the Packaged Products & $\% 50$ \\
Lack of Materials & $\% 7$ \\
Line Inefficiency & $\% 6$ \\
Lack of Data & $\% 6$ \\
Lack of Quality of Materials & $\% 5$ \\
Design Problem & $\% 5$ \\
Failure of Test Materials & $\% 4$ \\
Other Causes & $\% 17$ \\
\hline
\end{tabular}

$50 \%$ of the losses of manufacturing line was caused by the reprocessing of packaged products. Reprocessing activity should in fact be used in the Quality Part of the Overall Equipment Effectiveness calculation, but reprocessing decisions at the company are taken after production process is finished and rework is done on existing production lines. Production is stopped and the current production plan is changed. Reprocessing activities should be reduced through various quality activities. Reprocessing decisions are decisions made by the quality department during quality checks on a $2 \%$ random sample taken after packaging is finished. 
International Journal of Mathematical, Engineering and Management Sciences

Vol. 5, No. 6, 1128-1139, 2020

https://doi.org/10.33889/IJMEMS.2020.5.6.086

Table 7 shows the reasons for reprocessing the packaged products.

Table 7. Reasons for reprocessing the packaged products

\begin{tabular}{ll}
\hline Reasons for Reprocessing & Rate \\
\hline Errors in Assembly Line & $32 \%$ \\
Using Inappropriate Materials & $29 \%$ \\
Technical Problems & $21 \%$ \\
Errors in Printed Materials & $12 \%$ \\
Other & $6 \%$ \\
\hline
\end{tabular}

These wastes can be eliminated using different lean tools. All wastes can minimized or eliminated with Quality and Energy Circles, or Poka-Yoke applications. Overall Equipment Effectiveness (OEE), and 5S applications can be a solution for technical problems. If these reasons are eliminated, then the most important loss in the manufacturing line, namely, reprocessing the packaged products, is automatically eliminated. Within lean perspective, the waiting waste may be eliminated so as all these losses can be associated with waiting waste.

\section{Conclusion}

Energy efficiency in the industries is one of the leading problems of the 21 st century. Great efforts have been spent to assess energy efficiency. The main aim to deal with the energy efficiency paradigm is to save the resources in the manufacturing operations.

Manufacturing operations involve activities that creates wastes in any case; therefore, these wastes should be eliminated, or minimized as much as possible. Originated from the Toyota Production System (TPS), As Womack et al. (1991) highlighted seven significant types of waste to be eliminated in production processes, namely, overproduction, waiting, transportation, over specification, inventory, rework/scrap, and motion. Womack and Jones (2003) introduced an 8th waste, employee potential (Sagnak and Kazancoglu, 2016).

In this paper, it is aimed to integrate the energy efficiency term with lean management principles. The barriers and the drivers of the energy efficiency was discussed, and the 8 wastes within lean perspective were translated into energy counterparts. The main contribution of this study is to integrate the energy efficiency concept with lean approach. 8 wastes of lean approach were defined as energy efficiency perspective, and used as criteria. The study will reveal the important criteria using Fuzzy Analytic Network Process (Fuzzy ANP) method to make implications about how to eliminate these wastes.

The most important waste to provide energy efficient manufacturing process is found as overproduction with a weight of 0.229 . Waiting is found as the second important waste that has to be eliminated. The weight of it is 0.211 . Thirdly, transportation is found as another waste with a weight of 0.130 .

The limitation of this research is that, as with all multi criteria decision-making (MCDM) applications, the research includes subjective judgments. Further possible research could focus on employing different MCDM techniques.

\section{Conflict of Interest}

The authors confirm that there is no conflict of interest to declare for this publication. 
International Journal of Mathematical, Engineering and Management Sciences

Vol. 5, No. 6, 1128-1139, 2020

https://doi.org/10.33889/IJMEMS.2020.5.6.086

\section{Acknowledgements}

Authors express their sincere thanks to the 18 experts from kitchenware manufacturing company in Izmir, Turkey for pairwise comparisons.

\section{References}

Cagno, E., \& Trianni, A. (2013). Exploring drivers for energy efficiency within small-and medium-sized enterprises: first evidences from Italian manufacturing enterprises. Applied Energy, 104, 276-285.

Chai, K.H., \& Yeo, C. (2012). Overcoming energy efficiency barriers through systems approach-a conceptual framework. Energy Policy, 46, 460-472.

Chen S.J., \& Hwang C.L. (1992), Fuzzy multiple attribute decision making. In: Fuzzy Multiple Attribute Decision Making: Lecture Notes in Economics and Mathematical Systems, Springer, Berlin, Heidelberg.

Chung, S.H., Lee, A.H., \& Pearn, W.L. (2005). Product mix optimization for semiconductor manufacturing based on AHP and ANP analysis. The International Journal of Advanced Manufacturing Technology, 25(11-12), 1144-1156.

Environmental Protection Agency (EPA) (2011), Lean, energy and climate toolkit: achieving process excellence through energy efficiency and greenhouse gas reduction. https://www.epa.gov/sites/production/files/2013-10/documents/lean-energy-climate-toolkit.pdf, (Retrieved: 10.08.2018).

Gonce, A., \& Somers, K. (2010), Lean for green manufacturing. McKinsey \& Company Report. https://www.mckinsey.com/ /media/mckinsey/dotcom/client_service/Sustainability/PDFs/lean_green_ manufacturing.aspx (Retrieved: 08.08.2018).

Henriques, J., \& Catarino, J. (2016). Motivating towards energy efficiency in small and medium enterprises. Journal of Cleaner Production, 139, 42-50.

Hrovatin, N., Dolšak, N., \& Zorić, J. (2016). Factors impacting investments in energy efficiency and clean technologies: empirical evidence from Slovenian manufacturing firms. Journal of Cleaner Production, 127, 475-486.

Iftikhar, Y., Wang, Z., Zhang, B., \& Wang, B. (2018). Energy and CO2 emissions efficiency of major economies: A network DEA approach. Energy, 147, 197-207.

ISO 50001 (2011). Energy management systems - requirements with guidance for use. https://www.iso.org/obp/ui\#tiso:std:iso:50001:ed-1:v1:en Retrieved: (11.08.2018).

Lee, A.H., Kang, H.Y., \& Chang, H.J. (2008, October). Evaluating buyer-supplier relationships in high-tech industry by analytic network process (ANP). In 2008 IEEE International Conference on Service Operations and Logistics, and Informatics (Vol. 2, pp. 2677-2682). IEEE, Beijing.

Meade, L.M., \& Sarkis, J. (1999). Analyzing organizational project alternatives for agile manufacturing processes: an analytical network approach. International Journal of Production Research, 37(2), 241261.

Neto, J.Q.F., Walther, G., Bloemhof, J., Van Nunen, J.A.E.E., \& Spengler, T. (2009). A methodology for assessing eco-efficiency in logistics networks. European Journal of Operational Research, 193(3), 670682.

Ohno, T. (1988). Toyota production system: beyond large scale production. Productivity Press, New York, NY.

Olsthoorn, M., Schleich, J., \& Klobasa, M. (2015). Barriers to electricity load shift in companies: a surveybased exploration of the end-user perspective. Energy Policy, 76, 32-42. 
International Journal of Mathematical, Engineering and Management Sciences

Vol. 5, No. 6, 1128-1139, 2020

https://doi.org/10.33889/IJMEMS.2020.5.6.086

Opricovic, S., \& Tzeng, G.H. (2003). Defuzzification within a multicriteria decision model. International Journal of Uncertainty, Fuzziness and Knowledge-Based Systems, 11(05), 635-652.

Önüt, S., Kara, S.S., \& Işik, E. (2009). Long term supplier selection using a combined fuzzy MCDM approach: A case study for a telecommunication company. Expert Systems with Applications, 36(2), 3887-3895.

Patterson, M.G. (1996). What is energy efficiency?: concepts, indicators and methodological issues. Energy Policy, 24(5), 377-390.

Pusavec, F., Krajnik, P., \& Kopac, J. (2010). Transitioning to sustainable production-part I: application on machining technologies. Journal of Cleaner Production, 18(2), 174-184.

Reddy, B.S. (2013). Barriers and drivers to energy efficiency-A new taxonomical approach. Energy Conversion and Management, 74, 403-416.

Saaty, T. L. (2001). Decision making with dependence and feedback: the Analytic network process (2nd ed.). RWS Publications, Pittsburgh.

Saaty, T.L. (1980). The analytic hierarchy process, McGraw-Hill, New York.

Saaty, T.L. (1996). Decision making with dependence and feedback: the analytic network process. RWS Publications, Pittsburgh.

Saaty, T.L., \& Vargas, L.G. (1998). Diagnosis with dependent symptoms: Bayes theorem and the analytic hierarchy process. Operations Research, 46(4), 491-502.

Sagnak, M., \& Kazancoglu, Y. (2016). Integration of green lean approach with six sigma: an application for flue gas emissions. Journal of Cleaner Production, 127, 112-118.

Salonitis, K., \& Ball, P. (2013). Energy efficient manufacturing from machine tools to manufacturing systems. Procedia Cirp, 7, 634-639.

Schleich, J., \& Gruber, E. (2008). Beyond case studies: Barriers to energy efficiency in commerce and the services sector. Energy Economics, 30(2), 449-464.

Schudeleit, T., Züst, S., Weiss, L., \& Wegener, K. (2016). The total energy efficiency index for machine tools. Energy, 102, 682-693.

Souza, J.P.E., \& Alves, J.M. (2018). Lean-integrated management system: a model for sustainability improvement. Journal of Cleaner Production, 172, 2667-2682.

Thollander, P., \& Ottosson, M. (2008). An energy efficient Swedish pulp and paper industry-exploring barriers to and driving forces for cost-effective energy efficiency investments. Energy Efficiency, 1(1), 21-34.

Womack, J.P., \& Jones, D.T. (2003). Lean thinking: banish waste and create wealth in your corporation. Free Press, New York, NY.

Womack, J.P., Jones, D.T., \& Roos, D. (1991). The machine that changed the world: the story of lean production. Harper Collins, New York.

Zadeh, L.A. (1965). Fuzzy sets. Information and Control, 8(3), 338-353.

Zhou, L., Li, J., Li, F., Meng, Q., Li, J., \& Xu, X. (2016). Energy consumption model and energy efficiency of machine tools: a comprehensive literature review. Journal of Cleaner Production, 112, 3721-3734. 